\section{Evaluation of Volumetric Doses of Organs at Risk in Carcinoma Cervix Patients with HDR Intracavitary Brachytherapy and Comparison of CT- based and Conventional Plans}

\author{
Srivastava S. ${ }^{* *}$, Painuly N. K. ${ }^{2}$, Mishra S. P. ${ }^{3}$, Srivastava \\ K. ${ }^{4}$, Singh N. ${ }^{5}$, Singh S. ${ }^{6}$, Bhatt M. L. B. ${ }^{7}$
}

\begin{abstract}
Background: Brachytherapy treatment planning in cervix carcinoma patients using two dimensional (2D) orthogonal images provides only point dose estimates while CT-based planning provides volumetric dose assessment helping in understanding the correlation between morbidity and the dose to organs at risk (OARs) and treatment volume.
\end{abstract}

Objective: Aim of present study is to compare International Commission on Radiation Units and Measurements Report 38 (ICRU 38) reference point doses to OARs with volumetric doses using $2 \mathrm{D}$ images and $\mathrm{CT}$ images in patients with cervical cancer.

Material and Methods: In this prospective study, 20 patients with cervical cancer stages (IIB-IIIB) were planned for a brachytherapy dose of 7Gy per fraction for three fractions using 2D image-based treatment plan and CT-based plan. ICRU 38 points for bladder and rectum were identified on both 2D image-based plan and CTbased plan and doses $\left(\mathrm{D}_{\text {ICRU }}\right)$ at these points were compared to the minimum dose to $2 \mathrm{cc}$ volume $\left(\mathrm{D}_{2 \mathrm{cc}}\right)$ of bladder and rectum receiving the highest dose.

Results: $\mathrm{D}_{2 \mathrm{cc}}$ bladder dose was $1.60( \pm 0.67)$ times more than $\mathrm{D}_{\text {ICRUb }}$ bladder dose whereas $\mathrm{D}_{2 \mathrm{cc}}$ rectum dose was $1.13 \pm 0.40$ times $\mathrm{D}_{\text {ICRUr }}$. Significant difference was found between $\mathrm{D}_{\text {ICRUb }}$ and $\mathrm{D}_{2 \mathrm{cc}}$ dose for bladder $(\mathrm{p}=.0 .016)$ while no significant difference was seen between $\mathrm{D}_{\text {ICRUr }}$ and $\mathrm{D}_{2 \mathrm{cc}}$ dose for rectum $(\mathrm{p}=0.964)$.

Conclusion: The study suggests that ICRU 38 point doses are not the true representation of maximum doses to OARs. CT-based treatment planning is more a reliable tool for OAR dose assessment than the conventional 2D radiograph-based plan.

Citation: Srivastava S, Painuly N. K, Mishra S. P, Srivastava K, Singh N, Singh S, Bhatt M. L. B. Evaluation of Volumetric Doses of Organs at Risk in Carcinoma Cervix Patients with HDR Intracavitary Brachytherapy and Comparison of CT-based and Conventional Plans. J Biomed Phys Eng. 2019;9(6):603-612. https://doi.org/10.31661/jbpe.v0i0.867.

Keywords

Brachytherapy; Organs at Risk; Radiography

\section{Introduction}

Pervix cancer is one of the most common malignancy in women throughout the world. Radiotherapy, which involves external beam radiotherapy (EBRT) and intracavitary brachytherapy (ICBT), plays an important role in its treatment. Heterogenous dose distribution and the steep dose gradient in ICBT help to deliver greater doses to tumour and lesser doses to adjacent organs at risk (OARs)
${ }^{1} \mathrm{MSc}$, Assistant Professor Department of Radiotherapy, King George's Medical University,Lucknow,

Uttar Pradesh, India

${ }^{2} \mathrm{PhD}$, Professor of

Medical Physics, Depart-

ment of Radiotherapy

King George's Medical

University, Lucknow, Uttar

Pradesh, India

${ }^{3} \mathrm{PhD}$, Senior Scientist,

Department of Ra-

diation Oncology Dr.

Ram Manohar Lohia

Institute of Medical

Sciences,Lucknow, Uttar

Pradesh India

${ }^{4} \mathrm{MD}$, Professor of Ra-

diation Oncology, Depart-

ment of Radiotherapy

King George's Medical

University, Lucknow, Uttar

Pradesh, India

${ }^{5} \mathrm{PhD}$, Assistant Professor

of Medical Physics, De-

partment of Radiotherapy

King George's Medical

University, Lucknow, Uttar

Pradesh, India

${ }^{6} \mathrm{MD}$, Associate Professor

of Radiation Oncology, Department of Radiotherapy

King George's Medical

University, Lucknow, Uttar

Pradesh, India

${ }^{7} \mathrm{MD}$, Vice Chancellor,

Professor of Radiation

Oncology King George's

Medical University,

Lucknow, Uttar Pradesh,

India

*Corresponding author:

S. Srivastava

Assistant Professor, Department of Radiothera-

py, King George's Medi-

cal University,Lucknow,

Uttar Pradesh, India

E-mail: shraddha_srivas-

tava06@yahoo.com

Received: 19 November 2017 Accepted: 4 December 2017 
making ICBT an integral component of cervical cancer treatment $[1,2,3]$. A conventional method of planning involves the evaluation of dose to point $\mathrm{A}$, including bladder and rectum reference points as defined by International Commission on Radiation Units and Measurements (ICRU 38) using two dimensional (2D) orthogonal radiographs. However, these points do not represent a true estimate of doses received by the target and OAR volume. This may result in parts of target underdosed and misleading doses of OARs.

With the advancement of imaging modalities, identification of tumour dimensions, disease extent and delineation of OARs have become much easier. The use of three dimensional (3D) imaging techniques like Computed Tomography (CT) in treatment planning can give a better understanding of treatment outcome. CT-based treatment planning helps to evaluate volumetric doses to OARs and target through dose-volume histograms (DVHs). It allows to visualise $3 \mathrm{D}$ dose distribution in different volumes of OARs and the target, and helps in estimation of doses received by them; it also predicts normal tissues complications and treatment responses $[4,5]$.

Magnetic Resonance Imaging (MRI) being superior in image quality provides better information about the disease extent and tumour size. However, in the current study, it was not practical for every patient undergo MRI due to resource constraint. CT imaging, though less sensitive, yet easily available and affordable, can provide sufficient anatomical information. Considering the importance of 3D imaging, we carried out this study to compare ICRU point doses for bladder and rectum using 2D radiograph-based plans with volumetric doses to bladder and rectum respectively obtained from CT-based plans.

\section{Material and Methods}

In this prospective study, twenty patients of histopathologically proven cervical carcinoma with International Federation of Gynecology and Obstetrics (FIGO) staging from IIB to IIIB were treated with EBRT and High dose rate (HDR) ICBT between June 2015 and October 2016. A dose of 50 Gy in 25 fractions was delivered by EBRT using the box field technique, then brachytherapy was given after one week of completion of EBRT. A total of 60 ICBT applications were performed under general anaesthesia.

\section{Intracavitary Brachytherapy Treat- ment}

Each patient underwent three ICRT applications. Fletcher Williamson stainless steel applicators consisting of two ovoids (diameter $20 \mathrm{~mm}, 25 \mathrm{~mm}$ and $30 \mathrm{~mm}$ ) and a uterine tandem (angles $15^{\circ}, 30^{\circ}$ and $45^{\circ}$ ) were used. Different combinations of ovoids and tandem were used depending on patient anatomy. A Foley urinary catheter was inserted with its bulb inflated and filled with $7 \mathrm{cc}$ of contrast before each application to identify bladder point. After applicator insertion, guaze packing was done in anterior and posterior parts of vagina to fix the applicator position and displace bladder and rectum from the vaginal applicator. A customized rectal retractor with radio-opaque needle inside it was placed between the posterior vaginal wall and guaze packing to localize the posterior vaginal wall and identify ICRU rectal point.

\section{A. Two Dimensional Orthogonal Plan-} ning

Patients underwent 2D imaging (anteriorposterior and lateral) using orthogonal X-rays on the conventional simulator (Simulix Evaluation, Nucletron). Images were transferred to Oncentra Treatment planning system (TPS) through Digital Imaging and Communications in Medicine (DICOM) and treatment plans were generated. Point A, ICRU bladder point and ICRU rectal point were identified in treatment planning and also doses to point $\mathrm{A}$, bladder $\left(\mathrm{D}_{\text {ICRUb }}\right)$ and rectum $\left(\mathrm{D}_{\text {ICRUr }}\right)$ were recorded, respectively. ICRU bladder point was 
identified with the help of contrast filled Foley's bulb, while ICRU rectal point was defined $5 \mathrm{~mm}$ behind the posterior vaginal wall localized with the help of rectal retractor containing radiopaque material. Besides these points, doses to two additional points $1.5 \mathrm{~cm}$ above and below the ICRU bladder and four points $5 \mathrm{~mm}$ cranially and caudally to ICRU rectal point were recorded (Figure 1). The maximum dose received by every point was defined as $\mathrm{D}_{\text {Max }}$. Treatment was planned for three fractions prescribing a dose of $7 \mathrm{~Gy}$ per fraction to point A. Optimisation was done by changing dwell positions in plans where bladder or rectum doses were high.

\section{B. Three Dimensional CT Planning}

After taking informed consent, patients also underwent CT scan. CT scan of $5 \mathrm{~mm}$ slice thickness was done for each ICBT fraction of all patients using Philips, Brilliance CT simulator. CT images were transferred to TPS, then bladder, rectum and small bowel were delineated. The bladder contour included the outer wall of the bladder and ended at the beginning of the urethra. Rectum was defined from the top of two femoral heads to $3 \mathrm{~cm}$ superior to the anal verge. Intestines excluding sigmoid colon were contoured as the small bowel. Treatment planning was generated and DVHs were calculated for OARs. Same dwell positions were replicated as were in 2D plan. DVH parameters $\mathrm{D}_{2 \mathrm{cc}}, \mathrm{D}_{1 \mathrm{cc}}$ and $\mathrm{D}_{0.1 \mathrm{cc}}$ representing the minimum dose to maximum irradiated tissue volumes of $2 \mathrm{cc}, 1 \mathrm{cc}$ and $0.1 \mathrm{cc}$ were evaluated from DVH. Volumes corresponding to $50 \%$, $80 \%, 100 \%, 150 \%$ and $200 \%$ dose received by OARs were also reported. $\mathrm{D}_{2 \mathrm{cc}}$ doses for bladder and rectum were compared to ICRU point doses received by bladder and rectum.

\section{Statistical Analysis}

Paired t-test was used to compare the $\mathrm{D}_{2 \mathrm{cc}}$ volume dose of bladder and rectum with ICRU point dose received by bladder and rectum, respectively. The maximum point dose $\mathrm{D}_{\text {Max }}$ was also compared with $\mathrm{D}_{2 \mathrm{cc}}$ dose. Scatter plots were drawn based on above mentioned rela-

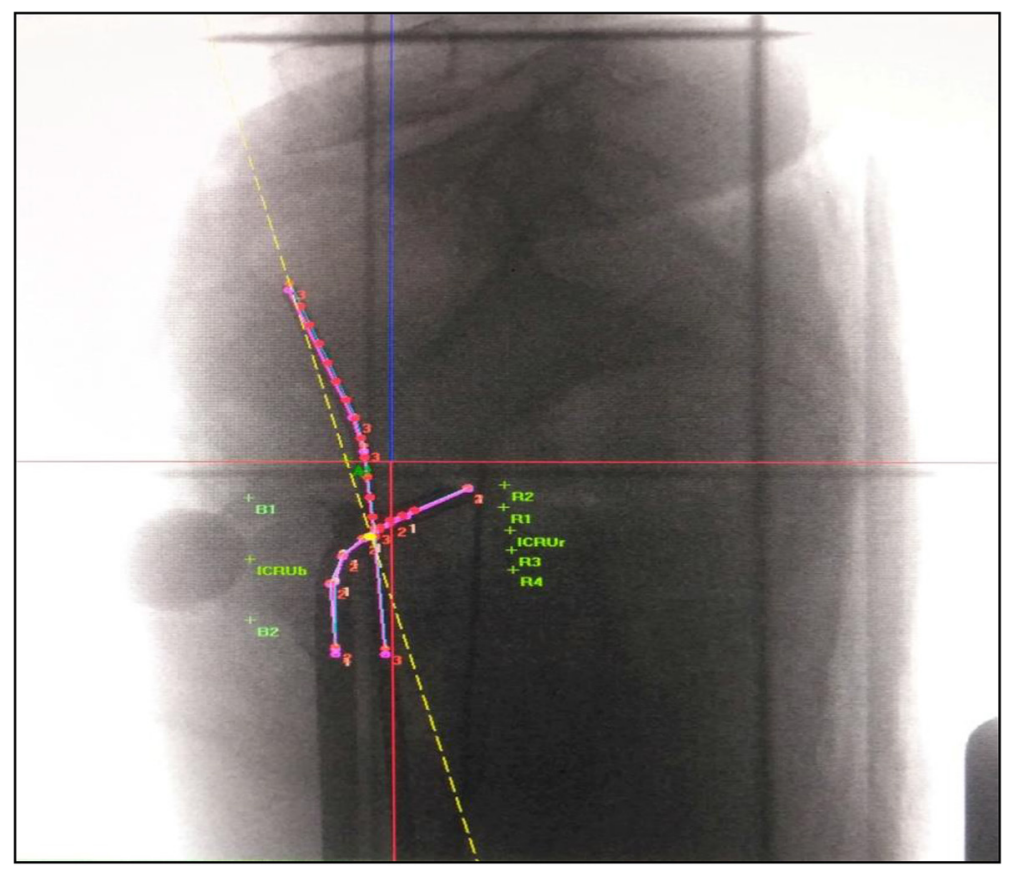

Figure 1: Orthogonal radiograph showing ICRU bladder and rectum point along with two points $1.5 \mathrm{~cm}$ above and below ICRU bladder point and four points $5 \mathrm{~mm}$ cranially and cadually from ICRU rectal point. 
tionships. Mean ratio $\mathrm{D}_{2 c \mathrm{c}} / \mathrm{D}_{\text {ICRU }}$ and the correlation between point $\mathrm{A}$ doses observed on $2 \mathrm{D}$ plan and CT-based plan were also found.

\section{Results}

60 intracavitary applications were studied. FIGO classification was used for tumour staging. 10 patients were from stage IIB, 1 from IIA and 9 patients from IIIB. Mean age of patients was 41years (range: 25-56 years), and activity of Ir-192 source ranged from 10Ci to $2 \mathrm{Ci}$. The total reference air kerma (TRAK) was $0.46 \pm 0.06 \mathrm{cGy}$ at $1 \mathrm{~m}$.

On comparison of point A doses from 2D plan and CT-based plan, it was found that they correlated well (Pearson correlation: -0.892). Table 1 demonstrates the ICRU point doses, $\mathrm{D}_{2 \mathrm{cc}}$ doses received by bladder and rectum and the ratio between $\mathrm{D}_{2 \mathrm{cc}}$ and $\mathrm{D}_{\text {ICRU }}$. The mean ICRU point dose $\mathrm{D}_{\text {ICRUb }}$ and mean minimal doses to $2 \mathrm{cc}$ volume, $\mathrm{D}_{2 \mathrm{cc}}$ for bladder were $4.92 \pm 1.89$ Gy (range 9.83) and 6.91 \pm 1.58 Gy (range 9.27 ) respectively while $\mathrm{D}_{\text {ICRUr }}$ and $\mathrm{D}_{2 \mathrm{cc}}$ for rectum were $4.58 \pm 1.15$ Gy (range 6.90) and $4.82 \pm 0.88$ Gy (range 4.14) respectively. $\mathrm{D}_{2 \mathrm{cc}}$ baldder dose is $1.60( \pm 0.67)$ times more than $\mathrm{D}_{\text {ICRUb }}$ bladder dose whereas $\mathrm{D}_{2 \mathrm{cc}}$ rectum dose is $1.13 \pm 0.40$ times $\mathrm{D}_{\text {ICRUr }}$. Statistical analyses showed significant differences between $\mathrm{D}_{\text {ICRUb }}$ and $\mathrm{D}_{2 \mathrm{cc}}$ dose for bladder $(\mathrm{p}=.0 .016)$ but no significant differences were seen between $\mathrm{D}_{\text {ICRUr }}$ and $\mathrm{D}_{2 \mathrm{cc}}$ dose for rectum $(\mathrm{p}=0.964)$. The volume of bladder and rectum receiving at least the ICRU point dose $\left(\mathrm{V}_{\text {ICRU }}\right)$ was found to be $11.05 \pm 8.25 \mathrm{cc}$ and $4.98 \pm 3.83 \mathrm{cc}$, respectively (Table 1).

Dose $\mathrm{D}_{\text {Max }}$ for bladder and rectum was found to be $5.43 \pm 1.35$ Gy (range 7.11) and $5.59 \pm 1.90$ Gy (range 8.65 ) respectively (Table 1$). \mathrm{D}_{2 \mathrm{cc}}$ for rectum was not significantly different from doses observed at maximal rectal point $(p=0.155) . D_{2 c c}$ for bladder, however, differed significantly from $\mathrm{D}_{\text {Max }}$ bladder $(\mathrm{p}=0.032)$. The mean volumes receiving 50\% (3.5Gy), 100\% (7Gy), 150\% (10.5Gy) and 200\% (14Gy) dose of prescribed doses in 2D plan and CT-based plan are depicted in Table 2, and these volumes were calculated using TRAK. Mean contoured

Table 1: Mean doses to ICRU points, $\mathrm{D}_{\text {Max }}$ point, $\mathrm{V}_{\text {ICRU }}$ and $\mathrm{D}_{2 \mathrm{cc}}$ volume of bladder and rectum.

\begin{tabular}{lll} 
& Bladder & Rectum \\
\hline Mean ICRU point dose $\left(\mathbf{D}_{\text {ICRU }}\right)(\mathbf{G y})$ & $4.92 \pm 1.89$ (range 9.83) & $4.58 \pm 1.15$ (range 6.90) \\
\hline Mean $\mathbf{D}_{\text {2cc }}$ dose $(\mathbf{G y})$ & $6.91 \pm 1.58$ (range 9.27) & $4.82 \pm 0.88$ (range 4.14) \\
\hline $\mathbf{D}_{2 \text { cc }}{ } \mathbf{D}_{\text {ICRU }}$ & $1.60 \pm 0.67$ & $1.13 \pm 0.40$ \\
\hline $\mathbf{D}_{\text {Max }}{ }^{* *}$ & $5.43 \pm 1.35$ (range 7.11) & $5.59 \pm 1.90$ (range 8.65) \\
\hline $\mathbf{V}_{\text {ICRU }}$ & $11.05 \pm 8.2$ & $4.98 \pm 3.83$
\end{tabular}

${ }^{*} \mathrm{D}_{\mathrm{Max}}$ - Maximum dose to point situated $1.5 \mathrm{~cm}$ superior to ICRU bladder point and to point situated $5 \mathrm{~mm}$ cranially to ICRU rectal point.

${ }^{* *} \mathrm{~V}_{\text {ICRU }}$ - Volume of bladder and rectum receiving at least the ICRU point dose.

Table 2: Mean volumes of different isodose curves obtained from 2D plan and CT-based plan.

\begin{tabular}{ccc} 
Dose Gy (\% of prescribed dose) & Vol. From 2D plan $\left(\mathbf{c m}^{3}\right)$ & Vol. from CT-based plan $\left(\mathbf{c m}^{3}\right)$ \\
\hline $3.5(50)$ & $237.79 \pm 61.28$ & $224.79 \pm 58.43$ \\
\hline $7(100)$ & $80.53 \pm 20.93$ & $76.77 \pm 19.95$ \\
\hline $10.5(150)$ & $42.95 \pm 11.16$ & $40.95 \pm 10.64$ \\
\hline $14(200)$ & $27.5 \pm 7.14$ & $26.22 \pm 6.81$
\end{tabular}


volumes of bladder, rectum and small bowel were $101.48 \pm 70.88 \mathrm{cc}, 53.68 \pm 16.58 \mathrm{cc}$ and $272.75 \pm 115.60 \mathrm{cc}$, respectively. Mean volumes of bladder, rectum and sigmoid receiving $50 \%$ (3.5Gy), 80\%, 100\% (7Gy), 150\% (10.5Gy) and $200 \%$ (14Gy) dose are mentioned in Table 3. Doses received by 1cc volume of bladder, rectum and small bowel are $7.73 \pm 1.56$ Gy, 5.32 \pm 0.97 Gy and 4.02 \pm 1.94 Gy, respectively while doses received by $0.1 \mathrm{cc}$ of bladder, rectum and small bowel are $8.70 \pm 1.58 \mathrm{~Gy}$, $6.31 \pm 1.12$ Gy and 4.82 \pm 2.22 Gy, respectively.

Figures 2 and 3 show the ratio of $D_{2 c c}$ to
$\mathrm{D}_{\text {ICRU }}$ for bladder and rectum for all intracavitary applications. Figures 4 and 5 are scatter diagrams showing correlations between $\mathrm{D}_{\text {Max }}$ and $\mathrm{D}_{2 \mathrm{cc}}$ for bladder and rectum, respectively.

\section{Discussion}

The conventional method of planning on 2D orthogonal radiographs is frequently used in ICBT. ICRU 38 report has been used for reporting point doses in intracavitary brachytherapy. It recommends to report the reference volume and evaluate doses to point $\mathrm{A}$, point $\mathrm{B}$, bladder and rectal reference points. However,

Table 3: Mean volumes of bladder, rectum and bowel receiving 50\%, $100 \%, 150 \%$ and $200 \%$ of the prescribed dose and mean contoured volume of bladder and rectum.

\begin{tabular}{cccc} 
Dose in \% of prescribed dose & Bladder & Rectum & Bowel \\
\hline $50 \%$ & $30.93 \pm 17.33$ & $9.83 \pm 3.64$ & $13.13 \pm 6.52$ \\
\hline $80 \%$ & $7.85 \pm 7.04$ & $3.63 \pm 1.95$ & $4.77 \pm 2.5$ \\
\hline $100 \%$ & $2.34 \pm 2.24$ & $0.58 \pm 0.51$ & $0.99 \pm 0.88$ \\
\hline $150 \%$ & $0.56 \pm 0.62$ & $0.12 \pm 0.28$ & $0.28 \pm 0.43$ \\
\hline $200 \%$ & $0.09 \pm 0.27$ & $0 \pm 0$ & $0 \pm 0$ \\
\hline Mean contoured volumes $\left(\mathrm{cm}^{3}\right)$ & $101.48 \pm 70.88$ & $53.68 \pm 16.58$ & $272.75 \pm 115.60$
\end{tabular}

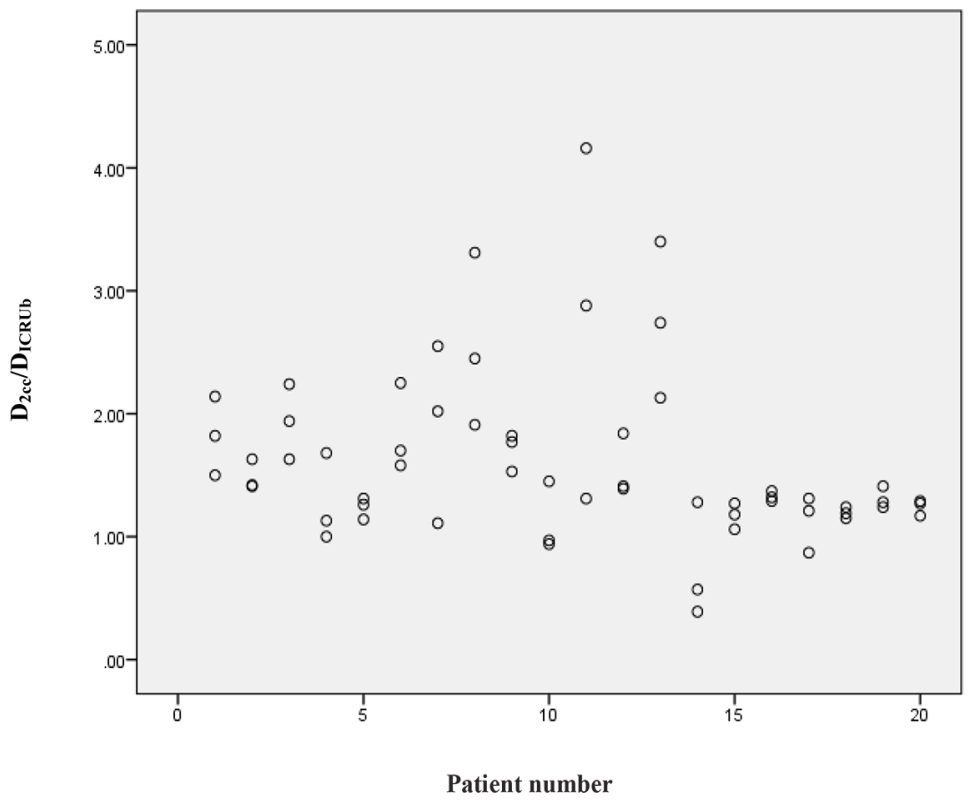

Figure 2: Ratio of $D_{2 c c^{\prime}}$ the dose received by the $2 \mathrm{~cm}^{3}$ of the volume of bladder to ICRU bladder reference point for all patients. 


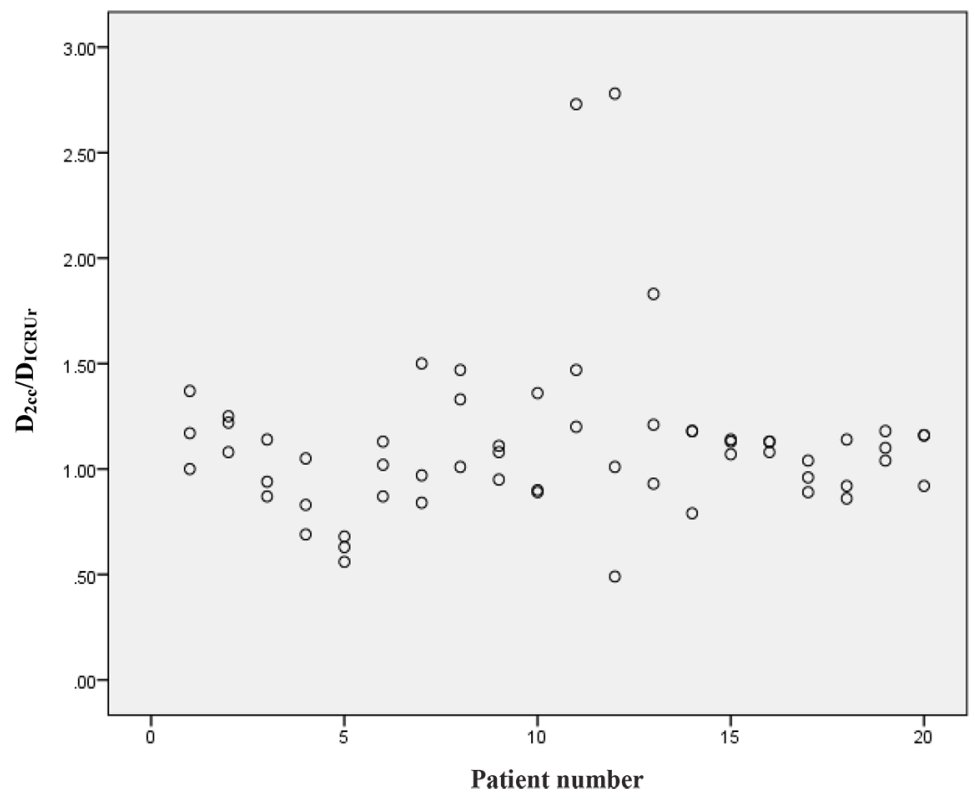

Figure 3: Ratio of $D_{2 c c^{\prime}}$ the dose received by the $2 \mathrm{~cm}^{3}$ of the volume of rectum to ICRU rectal reference point for all patients.

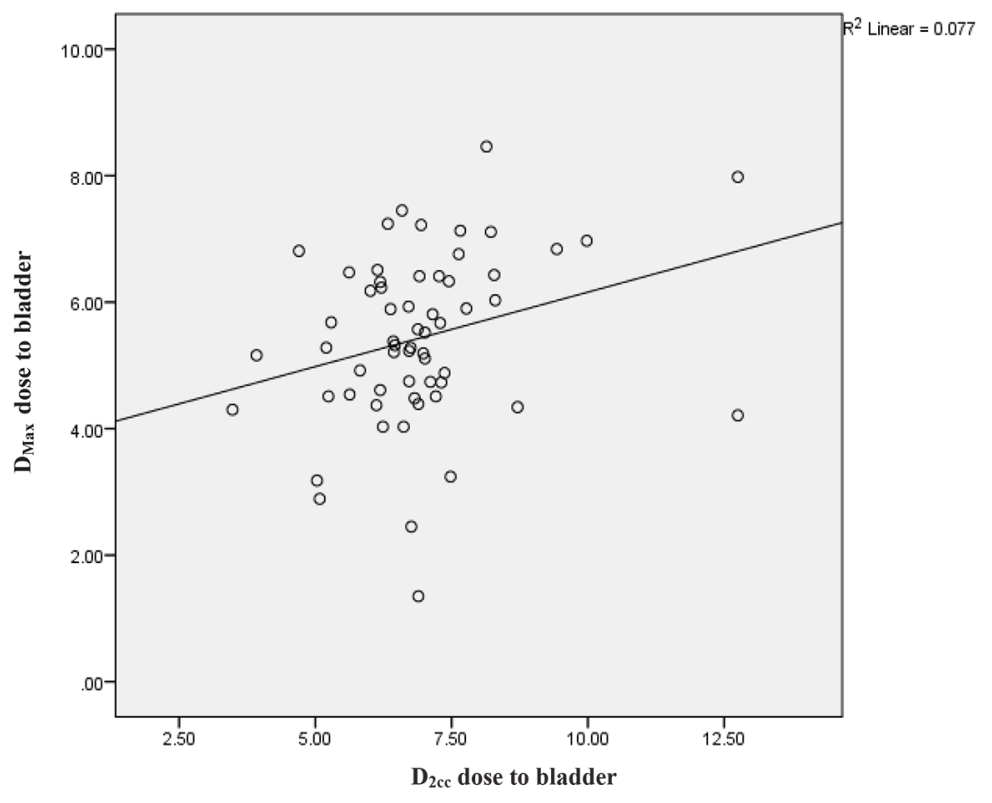

Figure 4: Scatter diagram depicting correlation between $D_{\text {Max }}$ and $D_{2 c c}$ bladder.

these points do not represent the true dose to organ volumes. Therefore, 3D imaging came into the role as it delineated targets and OARs easily and calculated dose-volume relationships possible through DVHs. In this study, we have tried to compare and correlate the ICRU point doses for bladder and rectum obtained from the conventional plan with volumetric doses from CT-based plan.

\section{Bladder}

Our findings suggest that for bladder, $\mathrm{D}_{\text {ICRUb }}$ 


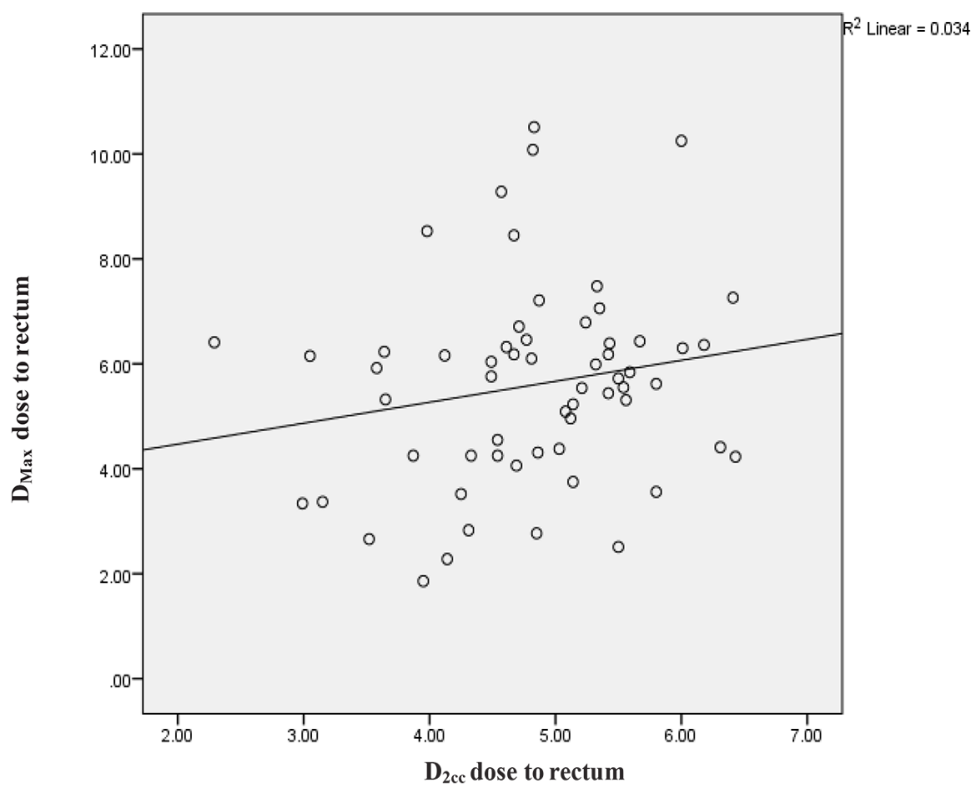

Figure 5: Scatter diagram depicting correlation between $D_{\text {Max }}$ and $D_{2 c c}$ rectum.

in 2D plan underestimated the dose to bladder. The maximum dose to bladder was found $1.60( \pm 0.67)$ times higher than ICRU bladder dose. Figure 2 illustrates this result. This value was similar to other studies. Tan et al. reported ICRU bladder point dose was less than $\mathrm{D}_{2 \mathrm{cc}}$ dose to bladder by a ratio of 1.34 [6]. Fellner et al. showed that $\mathrm{D}_{2 \mathrm{cc}}$ bladder dose was $1.4 \pm 0.5$ times ICRU bladder point dose [7]. Jamema et al. and Vinod et al. showed similar results $[2,8]$. There was significant difference found between $\mathrm{D}_{2 \mathrm{cc}}$ and $\mathrm{D}_{\text {ICRUb }}$ for bladder in the present study which was similar to results reported by other published studies [8, 9]. In our study, poor correlation was found between $\mathrm{D}_{2 \mathrm{cc}}$ and $\mathrm{D}_{\mathrm{ICRUb}}$ for bladder. Barrilot et al. using transabdominal ultrasound found that no correlation existed between ICRU point dose and $\mathrm{D}_{2 \mathrm{cc}}$ dose of bladder [10]. Significant difference was seen between $\mathrm{D}_{\mathrm{Max}}$ and $\mathrm{D}_{2 \mathrm{cc}}$ for bladder and there was no correlation between them which can be easily seen in Figure $4 . \mathrm{D}_{\mathrm{Max}}$ i.e. maximal point dose to bladder was higher than $\mathrm{D}_{\text {ICRUb }}$. This shows that ICRU bladder reference point does not represent the maximum point dose. In fact, the maximal point dose is situated $1.5 \mathrm{~cm}$ above the ICRU bladder point.

\section{Rectum}

$\mathrm{D}_{\text {ICRUr }}$ was similar to $\mathrm{D}_{2 \mathrm{cc}}$ dose of rectum in CT-based plan. The maximum dose to rectum was found to be $1.13( \pm 0.40)$ times the ICRU rectal point dose. This is visible in Figure 3. Other investigators showed similar results. Tan et al. showed ICRU rectal point underestimated $\mathrm{D}_{2 \mathrm{cc}}$ rectum dose by a mean ratio $\left(\mathrm{D}_{2 \mathrm{cc}} / \mathrm{D}_{\text {ICRUr }}\right)$ of 1.0 [6]. Pelloski et al. found that there was only a mean difference of $21 \mathrm{cGy} \pm 344$ cGy between $\mathrm{D}_{\text {ICRU }}$ and $\mathrm{D}_{2 \mathrm{cc}}$ rectum which was not significant and similar to our results [9]. No significant difference was observed between $\mathrm{D}_{2 \mathrm{cc}}$ and $\mathrm{D}_{\text {ICRU }}$ values of rectum which was in agreement with studies done by Kim et al. and Vinod et al $[8,11]$.

No correlation was observed between $D_{2 c c}$ and $\mathrm{D}_{\text {ICRUr }}$ for rectum in the present study. This was in agreement with few studies $[12,13$, 14]. $D_{\text {Max }}$ and $D_{2 c c}$ doses for rectum did not differ significantly in our study which it was similar to findings of Hashim et al. [5]. $\mathrm{D}_{\mathrm{Max}}$ and $\mathrm{D}_{2 \mathrm{cc}}$ for rectum showed no correlation which can be concluded from Figure 5 that this is dif- 
ferent from values found by Vinod et al. who showed that there existed a good correlation between $\mathrm{D}_{\max }$ and $\mathrm{D}_{2 \mathrm{cc}}$ for rectum [8].

$\mathrm{D}_{\text {Max }}$ for rectum was higher than $\mathrm{D}_{\text {ICRUr }}$ differed from studies done by Deshpande et al. [15] and Mahanshetty et al. [16] in which they said that there was no difference between maximal rectal dose point and ICRU rectum point. The difference in results could be due to improper vaginal packing causing shifts in the applicator position thereby changing the ICRU rectal point and changing the maximal rectal point with respect to changes in ICRU rectal point. However, Jason C et al. [17] showed that $\mathrm{D}_{\text {Max }}$ and $\mathrm{D}_{\text {ICRU }}$ points were different and the maximal rectal dose point was situated proximal in ICRU rectum point. This result was in line with our study.

\section{Small Bowel}

$\mathrm{D}_{2 \mathrm{cc}}$ dose to small bowel was not found, as traditionally it is not reported. Small bowel being a mobile organ can move in and out of the area to which the radiation dose is prescribed. Therefore it becomes difficult to find the dose received by the certain part of its volume during radiotherapy treatment. However it will be good to contour this organ for all such patients to have better ideas of toxicity.

Dose to $1 \mathrm{cc}$ and $0.1 \mathrm{cc}$ volume of bladder, rectum and bowel (Table 4) obtained from DVH of CT-based plan was found similar to results published by other investigators $[3,18$, 19] The reference volume in this study was calculated using TRAK. Other studies have

Table 4: Volume and doses of OAR from CTbased plan.

\begin{tabular}{cccc} 
Volume $\left(\mathbf{c m}^{3}\right)$ & Bladder & Rectum & Bowel \\
\hline $2 \mathrm{cc}$ & $6.91 \pm 1.59$ & $4.82 \pm 0.88$ & $3.58 \pm 1.76$ \\
\hline $1 \mathrm{cc}$ & $7.73 \pm 1.56$ & $5.32 \pm 0.97$ & $4.02 \pm 1.94$ \\
\hline $0.1 \mathrm{cc}$ & $8.70 \pm 1.58$ & $6.31 \pm 1.12$ & $4.82 \pm 2.22$
\end{tabular}

used different methods to find the reference volume. Esche et al. used milligram hours of radium to find out the the reference volume [20]. Deshpande et al. [15] calculated the reference volume using TRAK. In our study, volumes receiving $50 \%, 100 \%, 150 \%$ and $200 \%$ of point $A$ dose that have been found using TRAK were approximately same for both 2D orthogonal radiographs and CT-based plan. This was similar to results obtained by Jamema et al. [2]. However, different results were observed in the study done by Onal et al. [4] which showed larger mean isodose volumes for $50 \%$ and $100 \%$ isodose curves by CT-based plan were compared to conventional 2D plan. No difference was found for $150 \%$ and $200 \%$ isodose lines. Mean volumes of bladder, rectum and sigmoid receiving 50\% (3.5Gy), 80\%, 100\% (7Gy), 150\% (10.5Gy) and $200 \%$ (14Gy) dose were almost same as values obtained from the study done by Shin et al. and Fellner et al. [7, 21]. $\mathrm{V}_{\text {ICRU }}$ values (Table 1) were close to results from other published studies $[2,7,9]$.

\section{Conclusion}

Results of our study suggest that ICRU 38 point doses are not the true representation of maximum dose received by OARs in ICBT. These points should be used carefully while evaluating the dose to OARs. The three-dimensional image based on planning is a more reliable and useful tool for assessment of dose to normal structures. There is a need to practice the three-dimensional image based on brachytherapy to predict better treatment outcomes. The literature reporting doses to various points need a fresh outlook in Indian context due to anatomical size and variations. Reproducibility of applications and quality assurance are most critical parameters for accurate assessment of doses and have potential to improve treatment results.

\section{Conflict of Interest}

None 


\section{References}

1. Wachter-Gerstner N, Wachter S, Reinstadler E, Fellner C, Knocke TH, Wambersie A, et al. Bladder and rectum dose defined from MRI based treatment planning for cervix cancer brachytherapy: comparison of dose-volume histograms for organ contours and organ wall, comparison with ICRU rectum and bladder reference point. Radiother Oncol. 2003;68:269-76. PubMed PMID: 13129634.

2. Jamema SV, Saju S, Mahantshetty U, Pallad S, Deshpande DD, Shrivastava SK, et al. Dosimetric evaluation of rectum and bladder using imagebased CT planning and orthogonal radiographs with ICRU 38 recommendations in intracavitary brachytherapy. J Med Phys. 2008;33:3-8. doi: 10.4103/0971-6203.39417. PubMed PMID: 20041045; PubMed PMCID: PMC2786096.

3. Madan R, Pathy S, Subramani V, Sharma S, Mohanti BK, Chander S, et al. Comparative evaluation of two-dimensional radiography and three dimensional computed tomography based dosevolume parameters for high-dose-rate intracavitary brachytherapy of cervical cancer: a prospective study. Asian Pac J Cancer Prev. 2014;15:4717-21. PubMed PMID: 24969909.

4. Onal C, Arslan G, Topkan E, Pehlivan B, Yavuz $M$, Oymak $E$, et al. Comparison of conventional and CT-based planning for intracavitary brachytherapy for cervical cancer: target volume coverage and organs at risk doses. J Exp Clin Cancer Res. 2009;28:95. doi: 10.1186/1756-9966-2895. PubMed PMID: 19570212; PubMed PMCID: PMC2711061.

5. Hashim N, Jamalludin Z, Ung NM, Ho GF, Malik RA, Phua V. CT based 3-dimensional treatment planning of intracavitary brachytherapy for cancer of the cervix: comparison between dose-volume histograms and ICRU point doses to the rectum and bladder. Asian Pac J Cancer Prev. 2014;15:525964.

6. Tan YI, Choo BA, Lee KM. 2D to 3D Evaluation of Organs at Risk Doses in Intracavitary Brachytherapy for Cervical Cancer. J Contemp Brachytherapy. 2010;2:37-43. doi: 10.5114/jcb.2010.13721. PubMed PMID: 28031742; PubMed PMCID: PMC5183646.

7. Fellner C, Potter R, Knocke TH, Wambersie A. Comparison of radiography- and computed tomography-based treatment planning in cervix cancer in brachytherapy with specific attention to some quality assurance aspects. Radiother Oncol. 2001;58:53-62. PubMed PMID: 11165682.

8. Vinod SK, Caldwell K, Lau A, Fowler AR. A compar- ison of ICRU point doses and volumetric doses of organs at risk (OARs) in brachytherapy for cervical cancer. J Med Imaging Radiat Oncol. 2011;55:30410. doi: 10.1111/j.1754-9485.2011.02272.x. PubMed PMID: 21696566.

9. Pelloski CE, Palmer M, Chronowski GM, Jhingran A, Horton J, Eifel PJ. Comparison between CTbased volumetric calculations and ICRU referencepoint estimates of radiation doses delivered to bladder and rectum during intracavitary radiotherapy for cervical cancer. Int J Radiat Oncol Biol Phys. 2005;62:131-7. doi: 10.1016/j.ijrobp.2004.09.059. PubMed PMID: 15850913.

10. Barillot I, Horiot JC, Maingon P, Bone-Lepinoy MC, Vaillant D, Feutray S. Maximum and mean bladder dose defined from ultrasonography. Comparison with the ICRU reference in gynaecological brachytherapy. Radiother Oncol. 1994;30:231-8. PubMed PMID: 8209007.

11. Kim RY, Pareek P. Radiography-based treatment planning compared with computed tomography (CT)-based treatment planning for intracavitary brachytherapy in cancer of the cervix: analysis of dose-volume histograms. Brachytherapy. 2003;2:200-6. doi: 10.1016/j.brachy.2003.06.001. PubMed PMID: 15062127.

12. Ling CC, Schell MC, Working KR, Jentzsch K, Harisiadis L, Carabell $S$, et al. CT-assisted assessment of bladder and rectum dose in gynecological implants. Int J Radiat Oncol Biol Phys. 1987;13:1577-82. PubMed PMID: 3624031.

13. Schoeppel SL, LaVigne ML, Martel MK, McShan DL, Fraass BA, Roberts JA. Three-dimensional treatment planning of intracavitary gynecologic implants: analysis of ten cases and implications for dose specification. Int J Radiat Oncol Biol Phys. 1994;28:277-83. PubMed PMID: 8270452.

14. Van Den Bergh F, Meertens H, Moonen L, Van Bunningen $B$, Blom $A$. The use of a transverse CT image for the estimation of the dose given to the rectum in intracavitary brachytherapy for carcinoma of the cervix. Radiother Oncol. 1998;47:85-90. PubMed PMID: 9632298.

15. Deshpande DD, Shrivastav SK, Pradhan AS, Viswanathan PS, Dinshaw KA. Dosimetry of intracavitary applications in carcinoma of the cervix: rectal dose analysis. Radiother Oncol. 1997;42:163-6. PubMed PMID: 9106925.

16. Mahantshetty U, Tiwana MS, Jamema S, Mishra $S$, Engineer R, Deshpande D, et al. Additional rectal and sigmoid mucosal points and doses in high dose rate intracavitary brachytherapy for carcinoma cervix: a dosimetric study. J Cancer Res Ther. 
2011;7:298-303. doi: 10.4103/0973-1482.87027. PubMed PMID: 22044811.

17. Cheng JC, Peng LC, Chen YH, Huang DY, Wu JK, Jian JJ. Unique role of proximal rectal dose in late rectal complications for patients with cervical cancer undergoing high-dose-rate intracavitary brachytherapy. Int J Radiat Oncol Biol Phys. 2003;57:1010-8. PubMed PMID: 14575832.

18. Krishnatry R, Patel FD, Singh P, Sharma SC, Oinam AS, Shukla AK. CT or MRI for image-based brachytherapy in cervical cancer. Jpn J Clin Oncol. 2012;42:309-13. doi: 10.1093/jjco/hys010. PubMed PMID: 22348889.

19. Viswanathan AN, Dimopoulos J, Kirisits C, Berger D, Potter R. Computed tomography versus magnetic resonance imaging-based contouring in cervical cancer brachytherapy: results of a prospective trial and preliminary guidelines for standardized contours. Int J Radiat Oncol Biol Phys. 2007;68:491-8. doi: 10.1016/j.ijrobp.2006.12.021. PubMed PMID: 17331668.

20. Esche BA, Crook JM, Isturiz J, Horiot J-C. Reference volume, milligram-hours and external irradiation for the Fletcher applicator. Radiother Oncol. 1987;9:255-61.

21. Shin KH, Kim TH, Cho JK, Kim JY, Park SY, et al. CT-guided intracavitary radiotherapy for cervical cancer: Comparison of conventional point A plan with clinical target volume-based three-dimensional plan using dose-volume parameters. Int J Radiat Oncol Biol Phys. 2006;64:197-204. doi: 10.1016/j. ijrobp.2005.06.015. PubMed PMID: 16169676. 